\title{
Arte e afrobrasilidade como expoentes de luta e resistência
}

Art and afrobrasilidade as exponents of struggle and resistance

\section{Resumo}

Sirlene Ribeiro Alvesi Marcelino Euzébio Rodriguesii Universidade Federal do Rio de Janeiro

O texto dialoga com a produção cultural das artes visuais de artistas afro- brasileiros em quatro expoentes significativos para arte brasileira: o Barroco, período onde negros e seus descendentes criaram singularidades e especificidades no campo das artes; a Academia Imperial de Belas Artes, que mesmo sendo um ambiente eurocentrado integrou alguns artistas negros significativos e transgressores da ordem hegemônica; a Modernidade brasileira, momento de transformação na representação da população negra e a Contemporaneidade, onde as questões raciais assumem novos contornos políticos e afirmam posicionamentos militantes. Ancorados o referencial teórico sobre colonialidade QUIJANO (2009), MIGNOLO (2010), MALDONADO-TORRES (2007), nos estudos de CONDURU (2007, 2013), BAZIN (1993), DOSSIN (2000), ARAÙJO (2000) pretendemos evidenciar o trabalho de artistas negros, produzidos pela negociação, pelo conflito e pelo diálogo com as forças da hegemonia branca. Essas potências artísticas são, em primeira instancia, as primeiras lutas por representatividade no campo das artes visuais no Brasil.

Palavras-chave: Afrobrasilidade, artes visuais, história negra

\section{Abstract}

The text interacts with the cultural production of the visual arts of Afro-Brazilian artists in four significant exponents for Brazilian art: the Baroque period, where blacks and their descendants created singularities and specificities in the field of the arts; The Imperial Academy of Fine Arts, which, although it was a Eurocentric environment, integrated some significant black artists and transgressors of the hegemonic order; The Brazilian Modernity, a moment of transformation in the representation of the black population and Contemporaneity, where racial issues assume new political contours and affirm militant positions. Anchored the theoretical reference on coloniality QUIJANO (2009), MIGNOLO (2010), MALDONADO-TORRES (2007), in the studies of CONDURU (2007, 2013), BAZIN (1993), DOSSIN (2000), ARAJOJO (2000), we intend to evidence the Work of black artists, produced by negotiation, conflict and dialogue with the forces of white hegemony. These artistic powers are, in the first instance, the first struggles for representativeness in the field of visual arts in Brazil.

Revista Digital do LAV - Santa Maria - vol. 10, n. 2, p. 140 - 189 - mai./ago. 2017 ISSN 1983 - 7348 http://dx.doi.org/10.5902/1983734826911 
Palavras-chave: afro-Brazilian, visual arts, afro-Brazilian history

\section{Introdução}

É imensa a produção da população negra na Arte Brasileira, porém nas artes visuais isso é pouco valorizado, talvez porque o reconhecimento dessa linguagem seja mais complexo e elitizado. O fato é que o povo negro não foi somente representado nas pinturas, esculturas, fotografias, entre outras formas de visualidade, como também utilizou a linguagem plástica como uma forma de significação e ressignificação, de representatividade e resistência.

Da Silva (2005) chama a atenção para o preconceito dominante que considera o artista negro brasileiro como "primitivo" e "naïf" (ingênuo). As academias de arte europeias, por exemplo, sempre reforçaram a ideia de que a arte africana era "menor" em termos artísticos, por não se enquadrar aos dogmas preestabelecidos pelo classicismo, que relacionava o ideal de beleza à proporcionalidade da forma. Somente no modernismo é que alguns artistas começaram a dar valor às artes africanas. Entre eles, Pablo Picasso, que apresentou a potencialidade expressiva das máscaras ritualísticas, descobertas em uma de suas viagens à África.

A representação subalternizada do negro nas Artes Visuais, amplamente divulgada em livros didáticos, principalmente as obras de Debret e Rugendas, que passaram a ilustrar a escravidão no Brasil, trouxe algumas consequências negativas quanto a identificação e reconhecimento dessa parcela da população. A dor e o sofrimento mostrado em muitas dessas imagens, de certa maneira, delegou um lugar de submissão que contrasta com a verdadeira história de um povo que lutou e ainda se posiciona contra as desigualdades sofridas. As imagens que chegam à escola sobre o negro, publicadas no livro didático ou trazidas pelos professores, muitas vezes, ainda são aquelas em que artistas clássicos e modernos resumem a figura do negro a um ser exótico, além daquelas que retratam uma situação estigmatizada advinda da escravidão. É inegável a importância artística de muitas dessas imagens, como também o fato de denunciarem um período de opressão aos povos de origem africana.

De acordo com Alves: "Com o advento da lei 10.639/20031, e posteriormente da lei 11.645/2008, a junção Arte e etnia sai da condição de uma possibilidade tornando-se uma obrigatoriedade, o que propõe um novo olhar sobre o currículo de Arte (ALVES,

\footnotetext{
1 Em 2003 é realizada uma modificação na Lei de Diretrizes e Bases da Educação Nacional, estabelecendo a obrigatoriedade de ensino de História e Cultura Afro-brasileira no currículo escolar. O caráter políticopedagógico contido na referida lei contribui para que a população negra e seus descendentes se reconheçam, tenham a sua memória, sua história, cultura e identidade valorizadas no processo educacional.
} 
2013, p.141)", surgindo a necessidade de uma prática pedagógica que reforce a figura do negro como um produtor de arte e cultura.

Sobre a historiografia produzida por negros no Brasil, Fonseca nos aponta:

As concepções, que durante muito tempo imperaram na historiografia, reduziram os negros à condição de objetos. Um ser em situação de absoluta dependência, ao qual tudo era negado e que não possuía nenhuma capacidade de ação e reação dentro da sociedade escravista e patriarcal. A sua condição de sujeito não foi simplesmente negada, mas absolutamente desconsiderada em favor da descrição de um quadro que delimitava lugares sociais muito precisos para eles enquanto grupo racial. (FONSECA, 2007, p. 15)

Focalizando o negro, não como objeto de representação, mas como um agente artístico. Como um ser humano que se expressa pela arte, colocando seus pensamentos, suas ideias, seus questionamentos e sua concepção de vida em obras artísticas, sendo um agente cultural e artístico, que utilizou sua arte como um meio de resistência e luta contra as desigualdades sociais. Uma forma de empoderamento, um meio de ter voz e vez para enfrentar os obstáculos de sua realidade.

De uma forma ampla, a imagética afro-brasileira pode dialogar com as historias silenciadas, porque partem da margem sem o vicio excludente da colonialidade. Anibal Quijano (2009, p.73) afirma que colonialidade 'sustenta-se na imposição de uma classificação racial/étnica da população do mundo como pedra angular do referido padrão de poder e opera em cada um dos planos, meios e dimensões, materiais e subjetivos da existência social e da escala societal. Materializa-se no cotidiano dos povos silenciados por meio de agressões promovidas pelo poder imposto, manifestando-se através dos pensamentos e das práticas hegemônicas colonialistas onde as diferenças culturais são folclorizadas, renegadas e nunca consideradas legítimas. A colonialidade é uma tendência a universalizar e a validar apenas um tipo de conhecimento, que parte de único lugar de poder, como legítimo, a Europa. Diferente do colonialismo que vincula a ideia de dominação /exploração territoriais controlados pela autoridade, "a colonialidade se mantém viva nos manuais de aprendizagem, nos critérios para os trabalhos acadêmicos, na cultura, no senso comum, na autoimagem dos povos, nas aspirações dos sujeitos, em tantos aspectos da modernidade" (MALDONADO-TORRES, 2007, p.131).

Dessa forma, este estudo apresentará algumas histórias de negros que ultrapassaram ou questionaram o seu momento histórico através de sua atividade artística. Uma nova perspectiva para se observar, entender e até ensinar sobre a Arte no Brasil. Com isso, se deseja dar reconhecimento e visibilidade para a mão negra na arte, criando meios de valorização e identificação para maioria da população brasileira que é 
negra e que estão presentes em nossas salas de aula. Auxiliando na criação de um novo discurso pedagógico que evidencie as relações raciais, obras que não somente foram realizadas por negros, mas onde essas questões estão inseridas

Essas histórias estarão dividas em quatro vertentes significativas para arte brasileira: o Barroco, período onde os negros e seus descendentes foram importantíssimos para a criação de uma arte singular; a Academia Imperial de Belas Artes, ambiente extremamente formal que integrou alguns artistas negros; a Modernidade brasileira, momento de transformação na representação da população negra; e a contemporaneidade, onde as questões raciais assumem novos contornos.

\section{1- O Barroco brasileiro}

O Barroco surge como o estilo oficial da Contra-Reforma, contestando os dogmas da Reforma Protestante, tendo por objetivo "afirmar a grandeza da Igreja Católica mediante a produção de monumentos esplêndidos, mas também, por todos os recursos que estão ao alcance das artes figurativas, atestar a verdade da fé" (BAZIN, 1993, p.910). A religiosidade e a soberania de Deus também eram incentivadas pelas monarquias, que viam a possibilidade da utilização da fé como uma forma de controle e domínio de suas colônias. Conforme nos atesta Gombrich, "não foi somente a Igreja Romana que descobriu o poder da arte para impressionar e dominar. Os reis e príncipes da Europa estavam igualmente ansiosos por exibir seu poderio e aumentar assim a sua ascendência sobre a mente dos súditos" (1985, p.352).

Com a descoberta do ouro em Minas Gerais, essa se torna a mais rica capitania da Colônia. O florescimento do barroco mineiro é, de certa forma, incitado, para a submissão à Coroa, e propiciado pela riqueza.

Nesse momento, muitos descendentes de negros ganharam prestígio e admiração, tanto na pintura, na escultura, e na arquitetura, se tornando mestres em seus ofícios, como Mestre Valentim, Aleijadinho e Mestre Ataíde. A grande quantidade de artistas de origem simples, sendo a maioria negra e mestiça, é explicada por Dossin:

Sendo a arte entendida como uma atividade manual, consequentemente era uma prática inferiorizada pelos portugueses, pois o bom homem branco era também aquele que nunca tivera de lidar com ofícios vis do qual dependesse seu sustento. Assim sendo esta atividade era predominantemente desempenhada pelos africanos e seus descendentes. (DOSSIN, 2008, p. 246).

Desde o século XVI, os africanos já faziam parte de nossa estrutura social. Porém, na condição de escravos eram coibidos de perpetuar suas práticas religiosas, artísticas e 
culturais, e obrigados a utilizar sua força de trabalho na construção de signos religiosos e políticos de outra cultura:

Transportados forçadamente e escravizados, os africanos estiveram impedidos de reproduzir livremente suas culturas no Novo Mundo. Ao contrário, foram coagidos e incentivados a usar suas forças e talentos para construir os símbolos, o aparato físico e os elementos necessários às práticas sociais dos colonizadores (CONDURU, 2007, p. 15).

Assim, participaram na criação de cidades, edifícios militares e civis, mas principalmente em obras religiosas. A arte, para os mestres negros se tornou um meio trabalho e ascensão social, frente uma realidade e uma sociedade escravocrata.

Além desse aspecto, que por si só já representa uma informação relevante para a valorização da presença de negros na arte, esses artistas criaram modos de autorrepresentação e identificações. Mesmo tendo como base a arte europeia, muitas vezes se guiando por modelos vindos desses países, e seguindo seus cânones, esses artistas dialogaram com essa estética gerando uma arte cheia de singularidades, "os artistas mineiros criaram uma expressão própria do discurso barroco, expressão essa construída com o uso de matérias-primas locais e de novos modos de composição das obras" (Idem, p.52). A inserção de elementos iconográficos típicos de sua realidade, como caju e outras frutas, símbolos africanos, como búzios e chifres de carneiro, chegando a traços fisionômicos de alguns anjos e santos, como revelado alguns estudos.

$\mathrm{Na}$ conexão de afro-brasilidade à arte cristã, o dado que primeiramente salta aos olhos é a representação de santos e anjos com traços negroides, o amulatamento das figuras representadas em pinturas, retábulos e imagens católicas.(...) Autorrepresentações públicas toleradas, quiçá incentivadas, posto que implicavam conversão religiosa e cultural. (CONDURU, 2007, p. 18).

Como demonstrada por Felinto (2012), na pintura de Mestre Ataíde é exemplo disso. Manoel da Costa Ataíde (1762 - 1830), nasceu em Mariana - Minas Gerais, foi pintor, dourador e professor de arte, tendo papel fundamental na formação de novos artistas, e sendo nome de destaque na pintura desse período.

De pais portugueses, especula-se que a inspiração do artista venha de seus filhos e sua mulher que eram mestiços. No teto da Igreja de São Francisco de Assis em Ouro Preto, Mestre Ataíde pintou Nossa Senhora de Porciúncula com traços mestiços. Mesmo tendo um tom de pele mais claro, seus lábios e seu nariz revelam a negritude. De igual forma, os anjos em sua volta demonstram esse aspecto. 


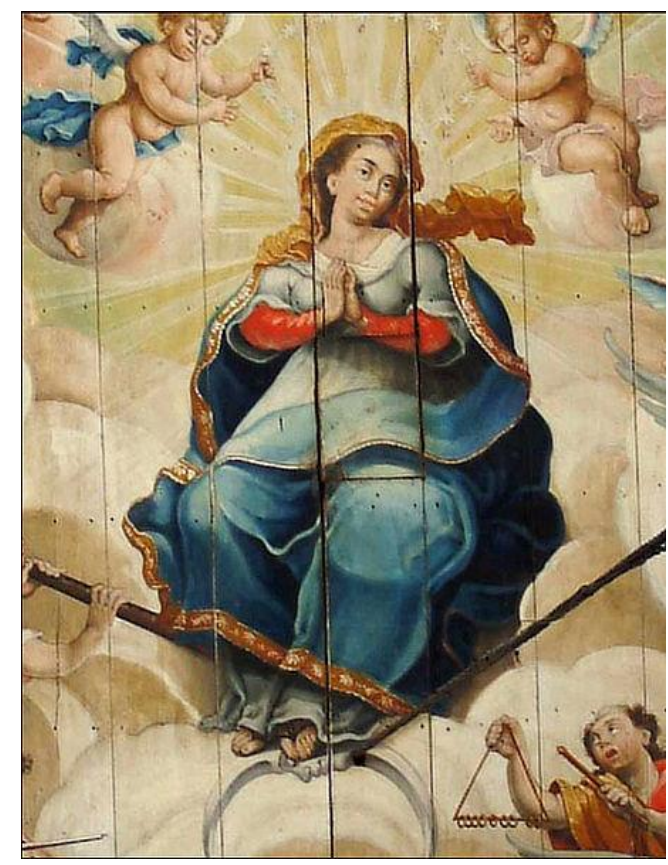

Figura.01

Manoel da Costa Athayde, 1801-1812 - Nossa Senhora de Porciúncula

Num momento histórico em que reina o sistema escravocrata, Mestre Ataíde foi um homem de destaque, assim como seus contemporâneos, Aleijadinho e Mestre Valentim. Esses dois últimos filhos de africanas com portugueses, também adquiriram reconhecimento e prestígio por suas obras artísticas, além de serem figuras importantes na transmissão do saber artístico. Mesmo utilizando modelos vindos da Europa e direcionados à uma religião e um aparato simbólico distante de suas raízes negras, esses artistas produziram uma arte original, aproximando de suas vivências.

\section{2- A Academia Imperial de Belas Artes}

A chegada da corte portuguesa, em 1808, muda o cenário artístico no Brasil. Houve a preocupação em modernizar culturalmente a nova sede do império português, a Missão Artística Francesa cumpria essa finalidade. Em 1816, é criada a Academia Real de Artes e Ofícios, e assim inaugurado o ensino formal de Arte. O neoclassicismo, como seu estilo oficial, trouxe os cânones artísticos da Europa e a necessidade de sistematização nos moldes europeus. Provocando um distanciamento entre a arte e o povo, entre a arte erudita e a arte popular, entre as belas artes e o artesanato.

Nesse momento, finda as encomendas por parte das confrarias que caracterizou o período do Barroco, e se inicia um novo período para os artistas trabalhadores negros, "com a progressiva institucionalização da arte, a inclusão do artista de origem africana 
tornou-se mais difícil, o que não quer dizer que ele estivesse ausente" (DOSSIN, 2008, p. 247).

Na paisagem oitocentista, marcada pela presença de artistas estrangeiros, e pela produção acadêmica, segundo Lima:

É fácil identificar uma presença negra quase como paisagem nos cenários brasileiros representados por artistas de diferentes tradições. O sistema escravagista associou a tonalidade escura da pele e fenotipias correlatas, imbricando ícones entre ser negro e ser escravo. Pois, os habitantes negros nas obras de professores da instituição como Jean Baptiste Debret mostram o interesse evidente pelos idos das primeiras décadas daquele século. (LIMA, 2008, p. 2-3).

Nessas produções, o olhar etnográfico, as classificações e a busca de registro de tipos e costumes, produziram uma compreensão e/ou uma identificação inferiorizada da população negra, muitas com sentido depreciativo e marcando o lugar do negro à margem da dinâmica social.

Porém, a população negra não permaneceu apenas nos modos de representação. Apesar de um maior distanciamento, artistas negros entraram nesse sistema de ensino, Firmino Monteiro, Estevão Silva, Rafael Pinto Bandeira e os irmãos João e Arthur Thimóteo da Costa, se inserido em um local extremamente seletivo, tendo a arte como meio de expressão e também subsistência.

Dentro dessa realidade, destaque-se o trabalho de Estevão Silva, primeiro pintor negro a se formar na Academia Imperial de Belas Artes. Filho de escravos africanos nasceu em Niterói em 26 de dezembro de 1845 (França, 2007), ingressando na Academia em 1864.

Poucos são os registros de sua vida privada, mas sua obra passa a ser revista no momento atual. Estevão se dedica a representação de naturezas-mortas, tema este visto com pouco prestígio dentro do cenário de exaltação nacional vividos no momento histórico, que privilegiava a construção da ideia de civilidade e nação priorizando o gênero de pintura histórica (França, 2007). Chegou a trabalhar com retratos, paisagens, temas religiosos e históricos, mas ganha visibilidade com suas naturezas-mortas.

Na Academia, foi aluno de Victor Meirelles, Jules Lê Chevrel, e Agostinho José da Motta, grandes nomes na arte nacional. Acredita-se que tenha herdado a apreciação pela representação de flores e frutos de Agostinho Motta. Sendo contemporâneo de Almeida Júnior, Rodolfo Amoedo, Belmiro de Almeida, Antônio Firmino Monteiro e Rodolfo Bernardelli.

Outro aspecto importante foi sua participação no Grupo Grimm. Formado pelos pintores Antônio Parreiras, Garcia y Vasquez, França Júnior, Francisco Ribeiro, 
Castagneto, Caron, o pintor alemão Thomas Driendl e liderados por Georges Grimm, esses jovens artistas se reuniam para pintar ao ar livre as praias e os arredores da cidade de Niterói. Esse método, o estudo da natureza pela observação direta e a pintura ao ar livre, não foi aceito pela Academia. Porém sua participação na década de 1880 não o fez romper esteticamente com a Academia.

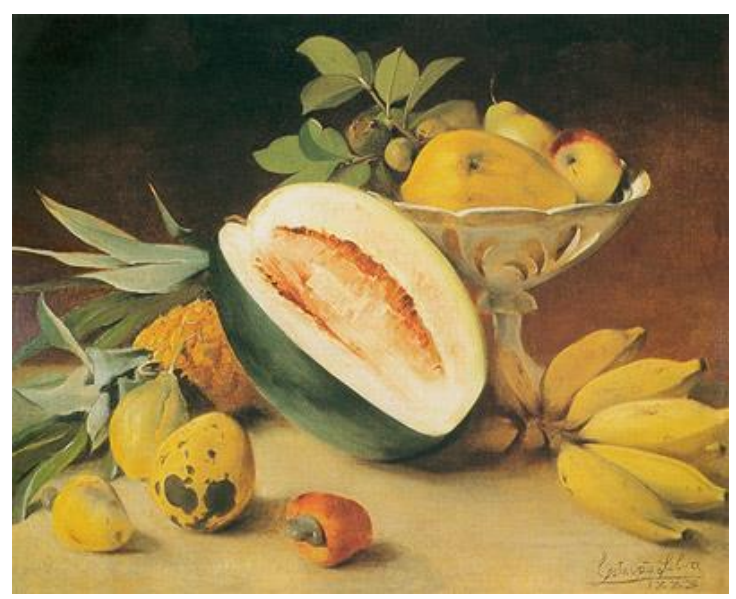

Figura.02

SILVA, Estevão. Natureza-Morta. 1888, óleo sobre tela, 90 x 84 cm. Disponível em Itaú Cultural

Recebeu algumas premiações, conquistando a medalha de prata nas exposições gerais de Belas Artes de 1876 e 1879, a medalha de ouro de segunda classe na exposição geral de Belas Artes de 1884 e o prêmio aquisição na exposição geral de 1890 . E impressionou a todos ao protestar publicamente, diante do Imperador D. Pedro II, por discordar da premiação destinada a ele na 25a Exposição Geral de Belas Artes. Por esse fato foi penalizado com um ano a suspensão dos estudos.

A participação de negros na academia ainda é questionada, conforme Conduru:

Embora haja muito ainda para saber do trabalho dos negros que se formaram na Academia Imperial e, depois, na Escola Nacional de Belas Artes, a autoimagem não parece ser a questão central, nem mesmo muito relevante em suas obras, que parecem ocupadas em exibir o domínio das ditas belas artes para atender aos anseios de uma clientela ocupada em mimetizar o gosto europeu. (CONDURU, 2007, p. 50).

É interessante pontuar que mesmo utilizando os códigos, o aparato simbólico, a técnica e o gosto da arte europeia, esses artistas representam a população negra em um espaço extremamente elitista. Apesar da origem humilde alcançam premiações, viagens à Europa, reconhecimento... Conseguem inserção nos circuitos de maior prestígio social 
da arte, as artes visuais. De qualquer forma, eles são agentes artísticos nesse momento, sujeitos que dialogam, se expressam e transmitem seus saberes artísticos.

Voltando o olhar para o trabalho artístico de Estevão da Silva, França (2007) pontua que o artista mostra peculiaridade ao representar frutas tipicamente brasileiras, como mangas, abacaxis, bananas, goiabas, frutas-de-conde, tangerinas, jabuticabas, romãs...

Essas frutas muitas vezes são típicas de clima tropical como o nosso e fazem parte de uma identidade diferenciada e do cotidiano do país. Com certeza não figuram na tradição pictórica da natureza-morta de frutas, que se concentra na representação de frutas de países temperados como as maçãs, as uvas, as pêras, morangos e framboesas, mas em frutas que estão relacionadas ao cotidiano do Brasil do século XIX. (FRANÇA 2007, p. 245)

Desse modo, Estevão não somente demonstra preocupação em satisfazer os anseios de um circuito de arte, como também pontua uma identidade, uma certa brasilidade em suas obras.

Relevante é o fato de que a Academia de Belas Artes, como mencionado anteriormente, não só instaura a institucionalização do ensino, mas reforça a separação entre as artes eruditas e a arte popular. Dentro da cultura popular, na arte realizada pelas camadas menos favorecidas da população, por artistas que não tiveram uma instrução formal, as contribuições das matrizes africanas sempre estiveram presentes, criando uma estética negra brasileira. Paralelamente à arte da academia, a presença do artista negro e a transmissão de seu saber permaneceram na arte popular, nas plasticidades das religiões afrodescendentes e no sincretismo das manifestações populares.

\section{3-Modernismo brasileiro}

É nessa perspectiva, de ultrapassar as convenções acadêmicas e se aproximar de uma arte mais abrasileirada, que no início do século XX um grupo de artistas instaura uma nova forma de representação para a população negra. Segundo Amaral, o modernismo brasileiro se constitui simultaneamente através de um movimento internacional e de outro nacional (2006). As influências dos movimentos modernistas internacionais podem ser percebidas em obras que dialogam com o impressionismo, com o cubismo, dadaísmo e outros movimentos, possibilitadas pelas viagens dos artistas brasileiros à Europa. Nesse período, no cenário internacional, houve uma redescoberta das formas e modos de representação dos povos considerados primitivos, que podem ser percebidos na arte de Gauguin e de Picasso. No Brasil, o modernismo era uma forma de 
atualizar as ideias estéticas, abolindo as formas e os cânones da representação acadêmica, dialogando com obras, movimentos e artistas estrangeiros. As viagens dos artistas modernistas permitiram esse contato, como também possibilitaram outro olhar sobre a realidade brasileira, permitindo uma nova consciência da realidade brasileira e a construção de uma arte nativa. A antropofagia foi utilizada como lema, já que desejavam ingerir influências artísticas do mundo e de nossa realidade, processá-las e transformálas em uma arte moderna especificamente brasileira.

Os estudos feitos por Mario de Andrade nas primeiras décadas do século XX (ANDRADE, 1993), abriram espaço para o surgimento de uma produção artística em que o negro começava a ser representado na obra de artistas com formação clássica, como Tarsila do Amaral, Di Cavalcanti, Portinari e Lasar Segall.

Nesse contexto, os modernistas estabeleceram um contato diferenciado com a arte popular, estabelecendo aproximações com artesões e artistas populares. Nesse contato, a representação de negros e da miscigenação, passou a ser constante na Arte:

o diferencial maior entre o modernismo vinculado à arte acadêmica e aquele que a ela pretendeu se opor é o valor do componente africano na formação da cultura brasileira. Em vez de negativa, degenerativa, a miscigenação étnica tornou-se positiva e mais: paradigma e emblema das relações culturais, artísticas. A atenção dada à cultura popular incentivou os artistas a olharem de modo especial algumas práticas e figuras oriundas das culturas africanas, as integrando ao ideário artístico formador da nação brasileira (CONDURU, 2007, p. 51).

Dessas aproximações entre o popular destacamos a obra de Heitor dos Prazeres. De acordo com Muniz Sodré, "o samba já não era, portanto, mera expressão musical de um grupo marginalizado, mas um instrumento efetivo de luta para afirmação da etnia negra no quadro da vida urbana brasileira" (SODRÉ, 1998, p. 16). Assim podemos pensar não somente esse estilo musical, manifestação artística escolhida por Heitor dos Prazeres no início de sua carreira, mas todas as obras deixadas por esse artista, desde música à pintura. Prazeres não foi simplesmente uma personalidade negra no mundo artístico, ele faz de sua arte um local de resistência da cultura de seu povo. Em suas obras, sejam elas musicais ou pictóricas, as tradições da cultura negra ganharam destaque e prestígio.

De família humilde, nasceu 10 anos após abolição dos escravos, em 1898. Filho de um marceneiro e clarinetista da banda da Guarda Nacional e uma costureira, foi criado na Cidade Nova, dos arredores da Praça Onze, área importante na disseminação e valorização da cultura negra carioca: "[o]s ofícios ensinados no início da vida de Prazeres foram aprendidos por ele por meio da transmissão compartilhada com membros mais 
velhos da comunidade, assim como fora sua vivência religiosa, corporal e musical na casa de tia Ciata" (D'AVILA, 2009, p. 20).

Será nesse ambiente que se desenvolverá, alcançando reconhecimento e prestígio primeiramente no meio musical. As artes plásticas chegam à sua vida na maturidade, por volta dos 38 anos. Segundo seu site oficial:

Com a morte da esposa em 1936, da paixão e tristeza de Heitor dos Prazeres surgiu uma nova maneira de se expressar artisticamente. O compositor descobriu o pintor ao ilustrar, através de um desenho colorido, sua mais nova criação musical: O pierrot apaixonado. (...)O compositor não conseguiu musicá-lo, porém mais tarde o pintor se inspiraria a criar um quadro com o nome do poema que Drummond Ihe dedicara: O Homem e seu Carnaval (1934). Este ilustre estudante e um outro - não menos ilustre estudante de jornalismo, além de desenhista, Carlos Cavalcante, foram, juntamente com o pintor Augusto Rodrigues, os incentivadores e lançadores do artista plástico Heitor dos Prazeres. Artista plástico porque sua plasticidade não se resumia ao desenho de figuras e às cores de sua pintura, abrangendo também a criação e confecção de instrumentos musicais de percussão, chegando até a costura - nos modelos de seus ternos, nas roupas de seu grupo de shows -, o mobiliário e a tapeçaria decorativall ([on line])

Apesar de longo e com muitas informações, o parágrafo destacado apresenta um artista versátil, caminhando por diversas linguagens (na música, na dança, nas artes visuais), que no contato com a cultura afro-brasileira e as trocas com intelectuais e artistas de sua época, constrói seu repertório. Em 1937 começa a expor incentivado pelos amigos, participando de exposições nacionais e internacionais, chegando a participar do Festival de Artes Negras em Dakar, realizado em 1966, ano de sua morte.

Sua vivência é nítida em suas obras plásticas, seus desenhos e pinturas apresentam a roda de samba, a macumba, o carnaval, as festas populares, além da geografia carioca, com seus bairros e favelas. De igual forma suas outras experiências artísticas se apresentam em suas composições plásticas: o ritmo do samba e o gingado de sua dança, na corporeidade das figuras, o carnaval nas cores de suas telas e nos personagens como o Pierrot.

Prazeres foi um autodidata, mas seu ofício foi compartilhado. Em seu ateliê contava com a ajuda de assistentes, trabalhando em esquema de oficina. Mas, a ele competia a criação das partes principais como rosto e gestos das figuras, lembrando a forma de trabalho dos artistas coloniais. Trabalhou com material variado como guache, aquarelas, pintura a óleo, madeira, tecido... Confeccionou cartões de Natal, estampas em tecido, pratos de madeira, atendendo a clientela variada, desde galerias a pessoas simples de sua própria comunidade. 
Sua produção pictórica foi analisada por críticos como Clarival do Prado Valladares, Rubem Braga, Carlos Cavalcanti e Carlos Drummond de Andrade, alguns desses passaram a ter uma grande amizade com artista. Foi considerado pela crítica como pintor primitivo, naïf e ingênuo. O termo primitivo foi utilizado na arte brasileira para incorporar alguns artistas negros, conforme a fala de Valladares,

A maior frequência de oportunidades para artistas de cor ocorre quando estes se identificam a determinado tipo de produção, permitido e aplaudido pelo público consumidor. E esta permissão e aplauso se referem à denominada arte primitiva, situada em termos de docilidade, de poeticidade anódina, na dose exata em que a pintura naïf deve comportar-se no conjunto das coleções ou das decorações de ambientes privados de aparente clima cultural, (VALLADARES, 1968, p. 101 ).

Sobre a ingenuidade de sua obra, sendo veiculada a inocência de crianças, D'AVILLA expõe "o estereótipo de pureza, ignorância e infantilidade impede o simples ato de perceber sutilezas, nuances da obra sob outras perspectivas, pois a produção de Heitor dos Prazeres, artista urbano, não diferia muito do que era produzido pelos modernistas" (D'AVILLA, 2009, p. 65). Já o termo naïf, ligado a seu autodidatismo, à temática popular e sua plasticidade visual, foi o termo mais aceito, principalmente pelo próprio artista.

A utilização desses termos pode remeter a outra questão importante em sua obra. É instigante pensar que nesse momento a temática negra é utilizada pelos artistas modernos contemporâneos a Prazeres. Porém não recebem o título de primitivo, naïf ou ingênuos. A questão racial e social pode se articular como uma forma de diferenciação para inclusão de pretos e mestiços nas artes visuais. Sobre isso, VALLADARES expõe:

Raros são os artistas pretos e mestiços que se afirmam sob critério crítico mais exigente, pois se conformam às regras do jogo sobre sua produção, que deverá ser ao gosto do consumidor. E este último, muitas vezes requer do - primitivoll ser homem de cor, preto, mulato ou índio, procedente da pobreza a fim de que a obra seja autêntica pela origem. Isto não corresponde à generalidade, mas uma das características da elite mandatária, em que os participantes procuram acrescentar, a si mesmos, uma aparência intelectual (VALLADARES, 1968, p.104).

Não podemos nos esquecer que o Modernismo brasileiro empregou a temática popular e negra, na busca por uma brasilidade. Porém, quando comparada a outros artistas que buscam a temática negra nesse período, sua obra ganha em autenticidade e veracidade. 
Cândido Portinari (1903-1962), o lituânio Lasar Segall (1891 - 1957) e Tarsila do Amaral (1886-1972) e Di Cavalcanti (1897-1976) tentaram evidenciar em suas pinturas a situação social e a individualidade do afro-brasileiro. Porém, deixaram nelas muitos traços de subalternidade. Por exemplo, no apelo exótico da Negra de Tarsila do Amaral (fig.3) revelando a manutenção do discurso hegemônico sobre a mulher negra, tratandoa como uma

alegoria (cristã) da maternidade e (afro-brasileira) da terra, um totem pagão cuja poesia emana da estranheza em face do outro primitivo e latente, mas é também alegoria nacional, cartaz publicitário, artigo de exportação, cromo patriarcal, mãe ancestral, "contraste de formas", fetiche sexual, manifesto modernista. (CONDURU, 2007, p. 48)

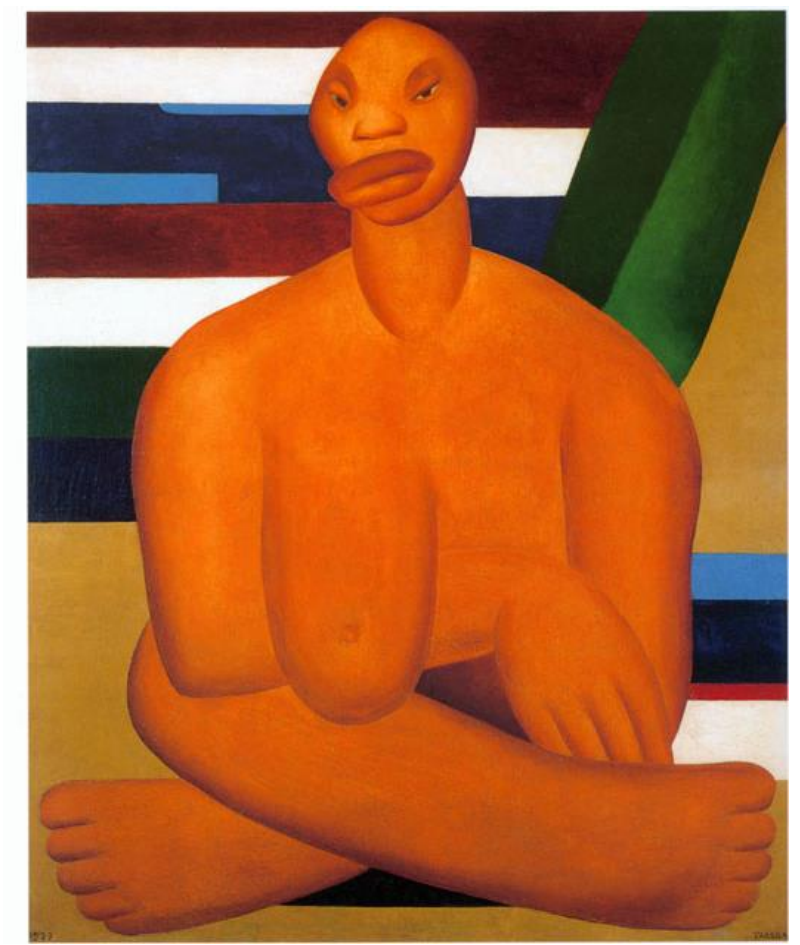

\section{Figura. 03 - A negra / Tarsila do Amaral, 1923 óleo sobre tela / $100 \times 81,3 \mathrm{~cm}$ Museu de Arte Contemporânea da Universidade de São Paulo, SP.}

No caso de Di Cavalcanti, é notório que "elegeu a mulata como paradigma de beleza nacional, com elegias pictóricas às mulheres afrodescendentes, subvertendo, por um lado, os padrões estéticos ocidentais impostos pela cultura bel artística, mas por outro, insistindo na objetivação sexual da mulher negra" (CONDURU 2007, p.58).

Munanga (2008) cita algumas palavras de Abdias Nascimento para falar sobre as origens do mulato brasileiro e o desfrute que ainda se faz desse estereótipo: 
- Brasil escravocrata herdou de Portugal a sua estrutura patriarcal de família, cujo preço foi pago pela mulher negra. $O$ desequilíbrio demográfico entre os sexos durante a escravidão, na proporção de uma mulher para cinco homens, conjugado com a relação assimétrica entre escravos e senhores, levou os últimos a um monopólio sexual das poucas mulheres existentes. Nesse contexto, as escravas negras, vítimas fáceis, vulneráveis a qualquer agressão sexual do senhor branco, foram, em sua maioria, transformadas em prostitutas como meios de renda e impedidas de estabelecer qualquer estrutura familiar estável. É absurdo apresentar o mulato que, na sua origem, é o fruto desse covarde cruzamento de sangue, como prova de abertura e saúde das relações raciais no Brasil. Ele evoca o ditado popular "branca pra casar, negra pra trabalhar, mulata pra fornicar", para apoiar a ideia geral de que a mulher negra foi prostituída. Já que a existência da mulata significa o produto do prévio estupro da mulher africana, a implicação está em que, após a brutal violação, a mulata tornou-se só objeto de fornicação, enquanto a mulher negra continuou relegada à sua função original, ou seja, o trabalho compulsório. Exploração econômica e lucro definem, ainda outra vez, seu papel social. (MUNANGA, 2008, p.86)

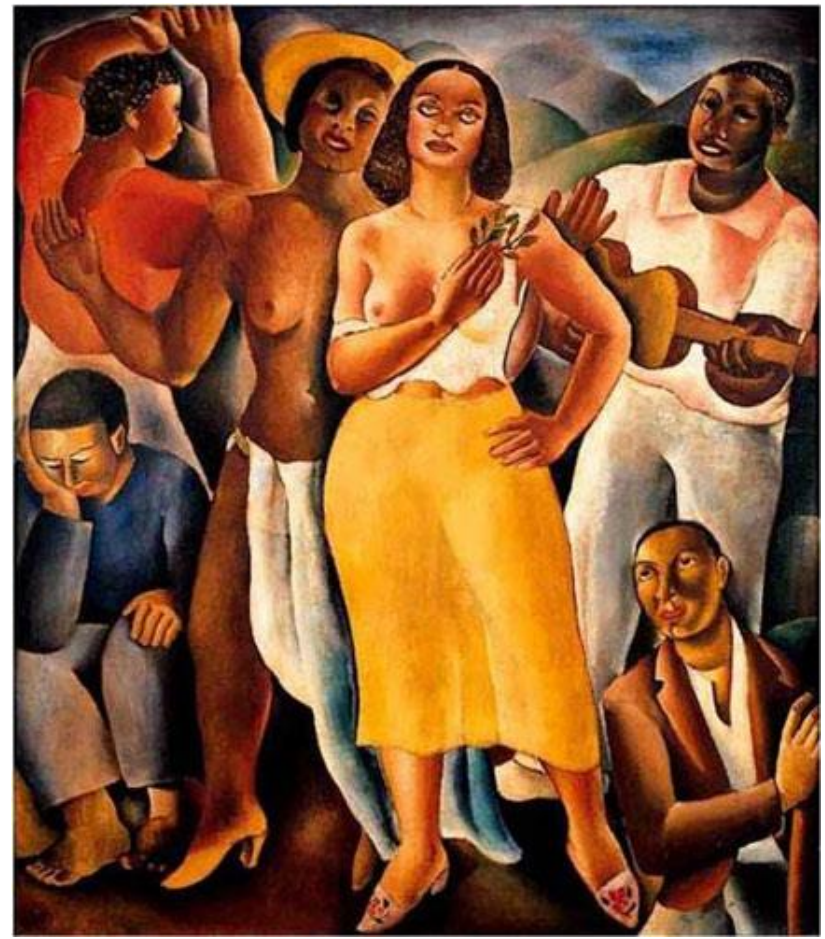

Figura. 04 -Samba / Di Cavalcanti, 1925 Óleo sobre tela / $177 \times 154 \mathrm{~cm}$ Coleção particular / Obra perdida em incêndio.

Azoilda Trindade (2005) fala do uso desses estereótipos nos dias de hoje. 
... essa tipologização entre a branca e a negra, de certa forma, perdura até os dias atuais, nas relações sociais, nos chistes, na propaganda, em particular, e no discurso midiático, em geral, pois a utilização de mulheres negras (e mulatas) seminuas facilita o consumo, o que marca, definitivamente, a construção de um discurso que vem determinando (reforçando) hegemonicamente os diferentes papéis ocupados pelas mulheres, brancas e negras, a partir de uma suposta pertença racial. (TRINDADE, 2005, p.87)

Para Nelson Fernando Inocêncio da Silva (2011) o racismo é fruto de um repertório de imagens recorrentes que são acessadas frequentemente.

O que são os estereótipos raciais senão uma construção histórica fundada em percepções visuais a priori? Percepções que fomentaram e lamentavelmente ainda fomentam as artes plásticas, a fotografia, o cinema, a televisão, o teatro, a literatura, a publicidade enfim. Até os classificados de emprego nas páginas dos jornais foram contaminados pelo questionável requisito da "boa aparência" que na prática se traduz em uma valorização absurda da imagem dos brancos como condição para o acesso ao emprego. A construção caricata do corpo negro vem, ao longo da formação deste país, habitando o imaginário da sociedade brasileira de maneira tão constante que mais parece uma marca indelével. Podemos facilmente nos deparar em pleno século XXI com imagens negativas sobre o povo negro que já eram recorrentes há mais de cinquenta anos atrás. A diferença de hoje é que tais abordagens não ocorrem mais da forma confortável como antes, em função do crescimento de uma consciência crítica atenta ao tamanho do estrago provocado. (DA SILVA 2011, p.14 e p.15)

Candido Portinari (Fig.5) representa, em grande parte das obras com essa temática, a imagem do afro-brasileiro como força de trabalho, como aquele que contribuiu para o desenvolvimento do país ou aquele morador da periferia e favelas. Como na obra de Portinari, observamos que ela caminha na vertente social e evidencia o trabalho dos colonos de uma fazenda de café de São Paulo, porém algumas figuras usadas como tema em sua obra, como o lavrador, o mestiço, os capatazes ou moradores de favelas são, em nosso entendimento figuras subalternizadas simbolizando a força de trabalho usada na economia brasileira. Ainda que o artista apresente o tema como homenagem e valorização, há de se pensar em sala de aula outras obras que evidencie a produção intelectual e cultural do negro e não apenas o trabalho braçal. 


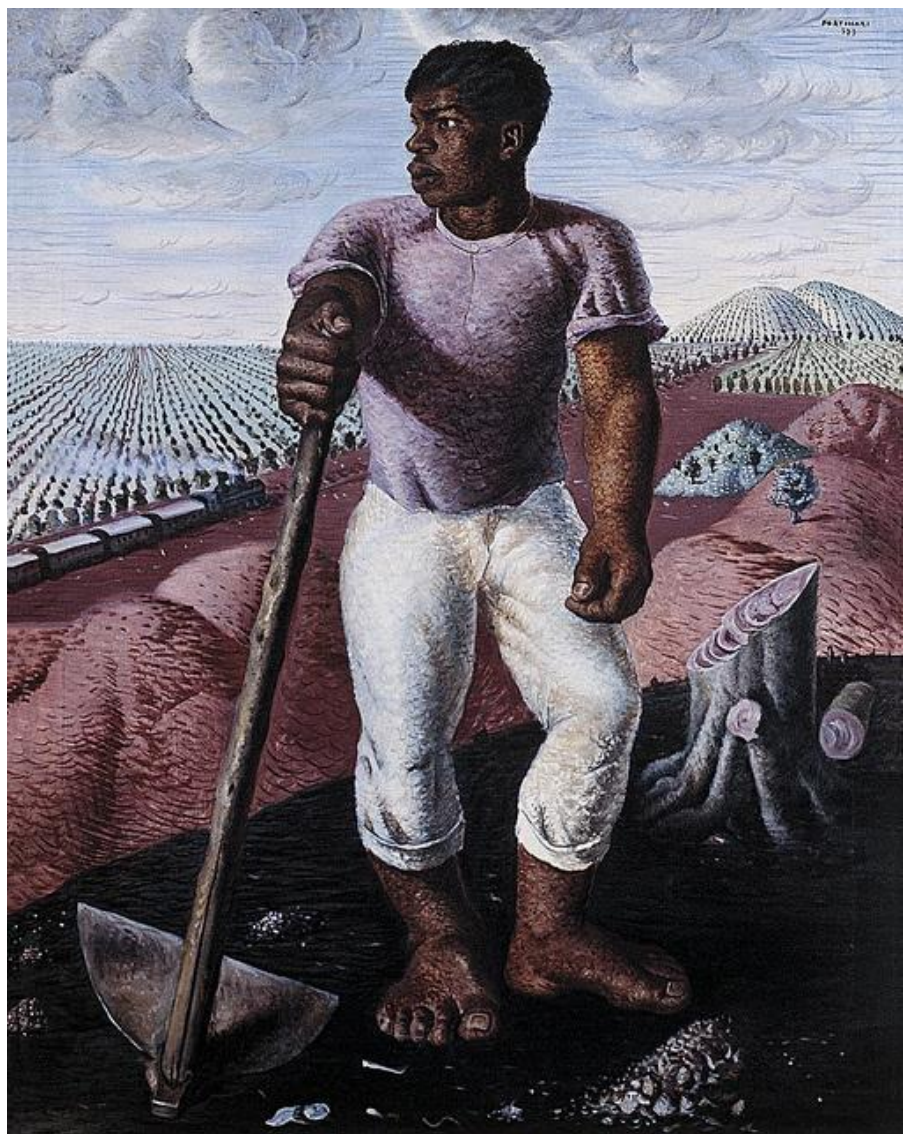

Figura.05 - Lavrador de café/ Candido Portinari, 1934 Óleo/ tela - $100 \times 81 \mathrm{~cm}$ Museu de Arte de São Paulo, SP

Voltando o olhar para Heitor dos Prazeres, podemos perceber que suas obras apresentam uma concepção diferenciada por representarem seu próprio povo e sua própria cultura. De acordo com D'AVILLA:

Ele retratava histórias e paisagens das quais fazia parte, distintamente de tantos artistas modernistas que iam ao mangue ou ao morro retratar algo que não Ihes pertencia, interpretando e apropriando-se de um elemento que não era deles, pintando temas de fácil sucesso comercial, como as mulatas de Di Cavalcanti.ll (D'AVILLA, 2009, p. 65).

Independente de nomenclatura, e de todo o debate gerado em torno delas, seus trabalhos marcam a presença do negro nas artes plásticas brasileiras, não somente por ser um artista negro, mas por inserir seu povo e cultura na arte. Dessa forma, o trabalho artístico de Heitor dos Prazeres pode ser compreendido como uma interpretação do próprio artista negro sobre sua gente e cultura. 


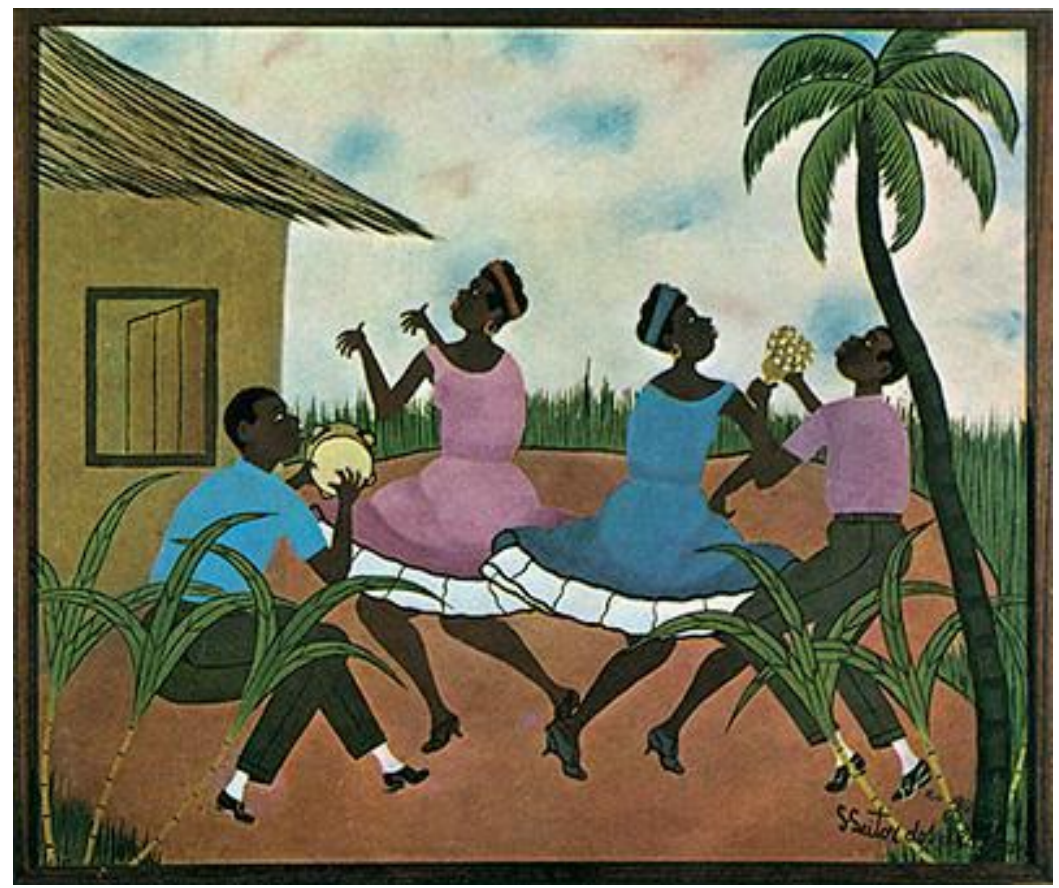

Figura 6 - PRAZERES, Heitor dos. Samba em Terreiro, s.d., óleo sobre tela, 54 x $65 \mathrm{~cm}$ Disponível em Itaú Cultural

\section{4- Contemporaneidade}

A arte contemporânea brasileira tem se apropriado do discurso político ligado a afrobrasilidade. A produção contemporânea

esparramou-se para além do campo especializado construído pelo modernismo e passou a buscar uma interface com quase todas as outras artes e, mais, com a própria vida tornando-se uma coisa espraiada e contaminada por temas que não são da própria arte.

(COCCHIARALE, 2007, p.16)

Produções que dialogam com o antirracismo, contra a subalternização do afrodescente e das religiosidades de matriz africana tem aparecido no campo artístico brasileiro. São trabalhos que forçam a não colonização da historia e a critica da arte, para a construção de subjetividades não coloniais (MIGNOLO, 2010, p.12)

A obra de Ayrson Heráclito, por exemplo, dialoga com narrativas implícitas da presença afrodescendente no Brasil, ora subvertendo a ordem colonial apontando o atlântico negro como rota de transculturação, flagelo do povo africano e a problemática da miscigenação, ora revelando as permanências das religiões de matriz africana e suas simbologias.

Na obra 'Trópicos' (fig.6) de Arjan Martins, exemplifica e discute poeticamente com a herança colonial do Brasil, não evidenciando ou exaltando um falso romantismo, 
mas desconstruindo e insurgindo uma discussão que discute o lugar e o não lugar do afrodescendente. Através de fragmentações de imagens, sua obra dialoga com o póscolonialismo, os fluxos migratórios dos africanos no período colonial, a desumanidade dos navios negreiros, as leis abolicionistas, a resiliências desses povos, sua escravização e seus dramas sociais.

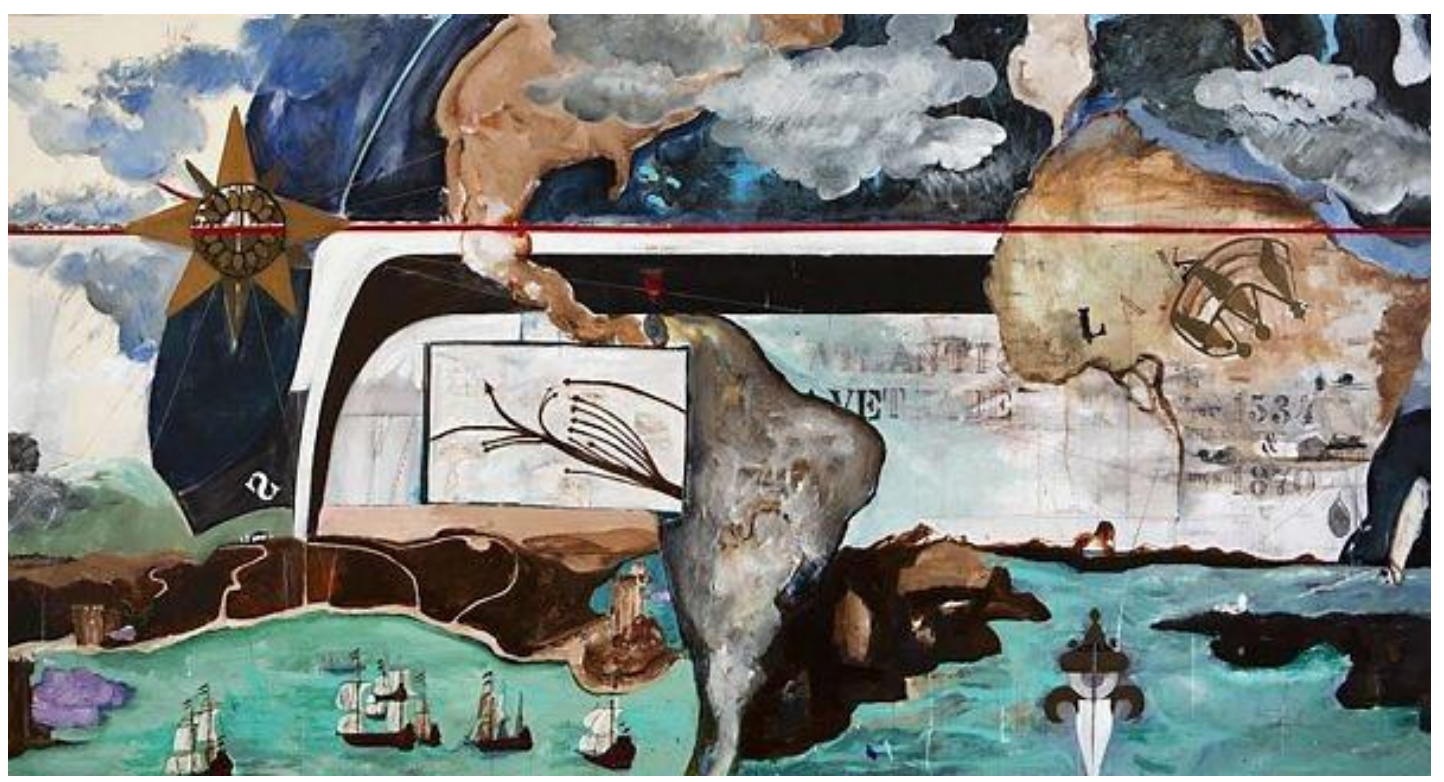

Figura.06 - Arjan Martins. 'Trópicos' 2014. Fonte: Veja Rio. Disponível em < http://vejario.abril.com.br/materia/cidade/arjanmartins-museu-de-arte-moderna/ > Acesso em 5/6/2015

A paulista Rosana Paulino (1967), dialoga com a história das mulheres negras no Brasil, ou com a história mulheres escravizadas no Brasil. Um exemplo de que a Arte contemporânea brasileira e principalmente aquela feita por afro-brasileiros é um dispositivo histórico pronto pra ser lido, apreciado e discutido sob diversos aspectos, em especial o sociológico e antropológico. Paulino trata diretamente de questões relacionadas ao ser mulher e negra como pontos de reflexão sobre a herança escravista e os estereótipos envolvendo a raça. Como na série "Bastidores", Paulino coloca em evidência a mulher negra discriminada, "proibida" de falar e ver, de participar do contexto social, de se fazer ouvir, excluída nos bastidores do cotidiano (COUTINHO, 2010).

Na série Atlântico Vermelho (fig.7), ela nos traz a visão do atlântico tingido pelo sangue, segundo ela 0

Revista Digital do LAV - Santa Maria - vol. 10, n. 2, p. 140 - 189 - mai./ago. 2017 ISSN 1983 - 7348 http://dx.doi.org/10.5902/1983734826911 
mar que liga dois pontos, África e Brasil, e cujas pontas sofreram processos de aniquilamento e subjugação das suas populações, tendo a ciência, a religião e a ideia de progresso sido usadas para justificar os mais aterrorizadores abusos. Tanto quanto as culturas, portanto, o que nos une também é o modo como estas estruturas foram utilizadas, criando uma triste história comum a ligar os dois lados do Atlântico².

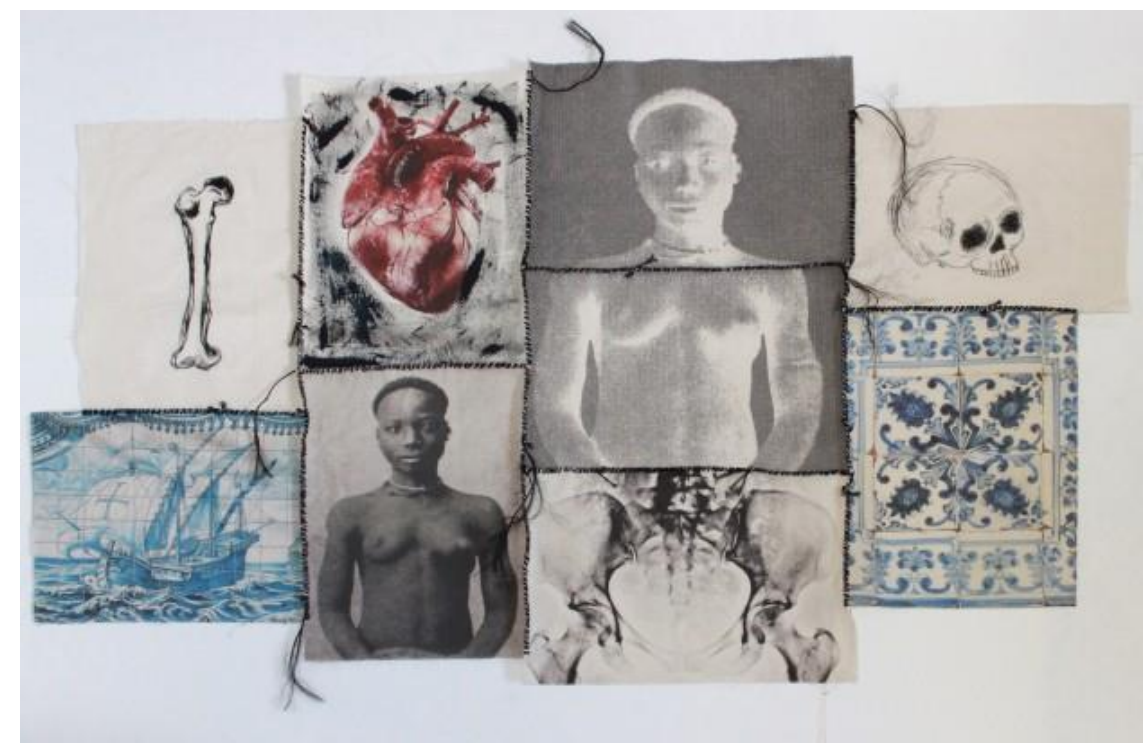

Figura.07 - Rosana Paulino, s/título, da série Atlantico Vermelho (2016). Impressão sobre tecido. Coleção particular.

A artista tenta recompor a história do trafico e da escravidão no Brasil juntando fragmentos que os referenciam, sendo o sangue, o povo africano e o domínio português as principais peças desse contexto. Na obra acima mencionada, a fotografia de uma jovem escrava em positivo e negativo nos faz pensar sobre o oculto dessa história e o que não se revela.

Assim como Paulino, outras artistas negras brasileiras também dialogam com as temáticas raciais e utilizam suas obras como força militante em lugares onde a arte se estabeleceu através de produções hegemônicas. São exemplos desses expoentes as artistas Maria Lídia Magliani (1946-2012) que pintou figuras que se diluem como a própria discussão racial no Brasil que se esvai e se silencia em meio a desconsideração das origens étnicas do país. Yêdamaria(1932-2016) produziu figuras quase míticas onde barcos, sereias e iemanjás trazem uma memória atávica da áfrica através de cores tênues. Sônia Gomes (1948) faz esculturas com panos, linhas e arames entrelaçados representando teias e rizomas que se formaram entre a África e o Brasil.

\footnotetext{
${ }^{2} \mathrm{Em}$ http://www.lisboacapitaliberoamericana.pt/?pg=article\&id=61 Acesso em 02/01/2017
} 
Outros nomes, não negros, mas de importância significativa nesse contexto histórico de diálogo entre afrobrasilidade e questões artísticas na contemporaneidade como Roberto Conduru sinaliza:

Além de alguns estrangeiros, artistas das mais diferentes regiões brasileiras, afrodescendentes ou não, atualizam e ampliam as frentes de ação abertas anteriormente nos diálogos entre artes visuais e afrobrasilidade, respondendo a questões artísticas e culturais contemporâneas. É grande a lista de nomes que podem ser citados: Adenor Gondim, Alexandre Vogler, Anna Bella Geiger, Antônio Sérgio Moreira, Artur Leandro, Ayrson Heráclito, Bauer Sá, Brígida Baltar, Caio Reisewitz, Ciça Fittipaldi, Cildo Meireles, Cláudio Kfé, David Cury, Denise Milan, Emanoel Araújo, Eustáquio Neves, Frente 3 de fevereiro, Guga Ferraz, Januário Garcia, Jorge dos Anjos, José Adário, Juarez Paraíso, Junior de Odé, Lena Martins e Associação Abayomi, Marcos Chaves, Marepe, Mário Cravo Neto, Maurício Dias e Walter Riedwig, Maurino Araújo,Martinho Patrício, Mestre Didi, Mônica Nador, Nêgo, Nelson Leirner, Regina Vater, Rodrigo Cardoso, Ronald Duarte, Ronaldo Rego, Rosana Paulino, Tonico Lemos Auad, Viga Gordilho, Walter Firmo e Wuelyton Ferreiro, entre outros". (CONDURU 2007, p. 31)

Sendo assim, a obra desses artistas surgem como um contraponto e reagem contra o ideário colonial, emergindo discussões sobre os lugares negados e falas silenciadas na sociedade brasileira. Seus autores são ou falam pelas mulheres e homens negros e contam historias que não querem ser ouvidas ou que foram relegadas pelo eurocentrismo, pelo sexismo ou racismo e se mostra em expansão com a abertura de mais artistas que aderem a essa discussão, tão emergente e necessária para a arte e para a educação.

\section{CONSIDERAÇÔES FINAIS}

Esse trabalho teve como objetivo dar visualidade às histórias e memórias da população negra contida em sua Arte, mostrando que, mesmo privados de seus reais direitos, os negros, seus descendentes, e até simpatizantes da causa (pessoas não negras, mas que se aproximaram dessa temática) buscaram meios de negociação e diálogo artístico.

Abordagens diferenciadas foram utilizadas nos diversos momentos históricos, mas que trazem o eixo comum de colocar-se plasticamente nas obras. No Barroco, se aproximando da plasticidade dominante, mas sem deixar de evidenciar as heranças físicas ou culturais dessa população. Na Academia, ainda sob o jugo da escravidão, se inserindo dentro de um contexto extremamente elitista e mostrando suas capacidades artísticas. Na Modernidade, aproximando e contrastando com a superficialidade do 
trabalho e do olhar de outro e de si próprio. E na contemporaneidade, tendo uma postura mais politizada, onde a arte pode ganhar tons de denuncia e protesto.

Assim, podemos compreender que as relações raciais ultrapassaram os modos de representação, os negros não somente foram retratados na arte, mas também utilizaram suas produções artísticas como meio de resistência e luta. Se expressando e se colocando através de obras artísticas, inserindo elementos de identificação (traços fisionômicos, símbolos religiosos e culturais), além questionar sua condição social através da Arte. Tornando-se sujeitos em seu tempo, agentes culturais e artísticos.

Favorecendo a construção de um novo modo de identificação e reconhecimento entre a população negra, seus antepassados e sua arte. Propiciando

\begin{abstract}
aos indivíduos oriundos de tais grupos informações que lhes possibilitem formar uma auto-imagem, uma auto-representação positiva, que sirva de contra-ataque às investidas deterioradas feitas à identidade grupal e individual a que estão sujeitos estes grupos. (SILVA, 1997, p. 48)
\end{abstract}

Cumprindo um dos principais objetivos da lei 10.639, que é reverter um processo que exclui, invisibiliza ou menospreza os conhecimentos, as histórias e memórias das populações negras. Histórias de luta e resistências, mesmo com direitos limitados, encontraram formas de transmissão e permanência cultural.

Se mudarmos o foco, a perspectiva, poderemos enxergar através da Arte, de suas obras, uma narrativa fascinante. De um povo que não se cala, nem se entrega, mas que ultrapassa os limites sociais que the aprisionaram para construir uma trajetória estética/cultural/artística singular. Desconstruindo estereótipos e preconceitos, e abrindo caminho para novas experiências e diálogos artísticos.

A fruição de uma Arte produzida por artistas afro-brasileiros em sala de aula, apresentado como expoentes pode levar à compreensão de que a produção cultural de nosso país se dá sob diversas mãos e não somente sob a europeia e que sua qualidade é equivalente, e por vezes, melhor. Araujo (2000, p.44) fala da importância desse tipo de abordagem para "desconstruir um imaginário que, primeiramente pelo olhar do estrangeiro e, depois, através da própria sociedade nacional, atuou de maneira poderosa na criação de estereótipos" nos quais se alicerça o discurso do preconceito que até hoje marca a identificação do negro no Brasil. É importante lembrar que a identidade construída pelo negro se dá não só por oposição ao branco, mas, também, pela negociação, pelo conflito e pelo diálogo com este. As diferenças implicam processos de aproximação e distanciamento. Nesse jogo complexo, vamos aprendendo, aos poucos, que as diferenças são imprescindíveis na construção da nossa identidade (GOMES, 2003, p.172). 


\section{Referências bibliográficas}

ALVES, Sirlene Ribeiro. O currículo de arte na educação de jovens e adultos á luz das leis 10.639/03 e 11.645/08. Revista Digital do LAV - Santa Maria - ano VI, n.10, p. 141-151 mar. 2013.

ANDRADE, Mário de. Fotógrafo e Turista Aprendiz. São Paulo: Instituto de Estudos Brasileiros, 1993.

ARAUJO, Emanoel. Negro de Corpo e alma. In: AGUILAR, Nelson. Mostra do Redescobrimento: Negro de Corpo e Alma. Fundação Bienal de São Paulo. São Paulo: Fundação Bienal de São Paulo, 2000.

BAZIN, Germain. A arquitetura barroca no Brasil. Rio de Janeiro: Editora Record, 1983

DA SILVA, Maria José Lopes. As Artes e a diversidade étnico-cultural na escola básica. In: Superando o Racismo na escola. MUNANGA, Kabengele (Org.) Brasília: MEC/BID/UNESCO, 2005.

DA SILVA, Nelson Fernando Inocêncio. Os fios que nos unem: Tecendo conhecimentos sobre a Lei 10639/03. Anais do I Colóquio Interestadual "Histórias e culturas africanas e afro-brasileiras na escola". São Paulo: Governo do estado de São Paulo, 2011. Disponível em <http://www.simposio.cpscetec.com.br/ISBN-978-85-99697-13-9-2011.pdf>. Acesso em 2/ janeiro/ 2017.

COCCHIARALE, Fernando. Quem tem medo de Arte Contemporânea. Recife: Massangana, 2007.

CONDURU, Roberto. Arte Afro-Brasileira. Belo Horizonte: C/Arte, 2007.

Cruzando o Atlântico e outros hiatos: ligações artísticas entre Brasil, África e além. Artafrica. Disponível em: <http://www.artafrica.info/html/artigotrimestre/artigo.php?id=38>. Acesso em: 14 abr. 2013.

D 'AVILA, Patrícia Miranda. Primitivo, Naïf, ingênuo: um estudo da recepção e notas para uma interpretação da pintura de Heitor dos Prazeres. Dissertação de Mestrado, USP, $2009 . \quad$ Disponível em: <http://www.dominiopublico.gov.br/pesquisa/DetalheObraForm.do?select_action=\&co_o bra $=200651>$. Acesso em 15 jul. 3014.

DOSSIN, Francielly Rocha. Apontamentos acerca da presença do artista afro-descendente na história da arte brasileira. $17^{\circ}$ Encontro Nacional da Associação Nacional de Pesquisadores em Artes Plásticas Panorama da Pesquisa em Artes Visuais. Disponível em: <http://www.anpap.org.br/anais/2008/artigos/024.pdf>. Acesso em: 14 ago. 2013. 
FONSECA, M. A arte de construir o invisível: o negro na historiografia educacional brasileira. In Revista Brasileira da História da Educação. São Paulo: Sociedade Brasileira de História da Educação, n. 13 jan-abr, 2007.

Concepções e práticas em relação à educação dos negros no processo de abolição do trabalho escravo no Brasil (1867-1889). Dissertação de Mestrado. Belo Horizonte: UFMG, 2000.

GOMES, Nilma Lino. Educação, identidade negra e formação de professores/as: um olhar sobre o corpo negro e o cabelo crespo. Educação e Pesquisa, São Paulo, v.29, n.1, p. 167-182, jan./jun. 2003.

LIMA, Heloisa Pires. A presença negra nas telas: visita às exposições do circuito da Academia Imperial de Belas Artes na década de 1880. 19\&20, Rio de Janeiro, v. III, n. 1, jan. 2008. Disponível em: <http://www.dezenovevinte.net/obras/obras negros.htm>. Acesso em: 30 out. 2014.

MALDONADO-TORRES, Nelson. Sobre La colonialidad Del ser: contribuiciones al desarrolo de um concepto. In: CASTRO-GOMEZ, Santiago; GROSFOGUEL, Ramón (orgs.). El giro decolonial. Reflexiones para uma diversidad epistêmica más Allá Dell capitalismo global. Bogotá: Iesco-Pensar, 2007. P.127-167

MIGNOLO, Walter. Aiesthesis decolonial. Revista CALLE14 . Volume 4, número 4. JaneiroJunho de 2010. Disponível em

$<\quad$ https://artlabourarchives.files.wordpress.com/2012/08/mignolo-aiesthesisdecolonial.pdf $>$ Acesso em 1/06/2017

MUNANGA, Kabenguele. Rediscutindo a mestiçagem no Brasil. Belo Horizonte: Autêntica, 2008.

OLIVEIRA, Luiz Fernandes de. História da África e dos africanos na escola: desafios políticos, epistemológicos e identitários para a formação dos professores de história. Rio de janeiro: Imperial Novo Milênio, 2012.

QUIJANO, Aníbal. Colonialidade do poder e classificação social. In: SANTOS, Boaventura de Sousa e MENEZES, Maria Paula (Orgs.). Epistemologias do Sul. Coimbra: Edições Almedina, 2009, p.73-117.

SILVA, Dilma de Melo. Identidade afro-brasileira: abordagem do ensino da arte. Comunicação \& Educação - Revista do curso Gestão da Comunicação. v. 3, n. 10. p. 4449.

TRINDADE, Azoilda Loreto. A Formação da Imagem da Mulher Negra na Mídia. Tese de Doutorado. Centro de Filosofia e Escola de Comunicação. Rio de Janeiro: UFRJ, 2005.

VALLADARES, Clarival do Prado. O negro brasileiro nas artes plásticas. Cadernos Brasileiros, ano X. Rio de Janeiro, maio-julho, 1968. In: Catálogo Mostra do Redescobrimento - Brasil 500. São Paulo: Associação Brasil 500 anos Artes Visuais, p 100-110. 
${ }^{\mathrm{i}}$ Formada em História da Arte pela Universidade Estadual do Rio de Janeiro, especialista em Educação de Jovens e Adultos pela Universidade Federal do Rio de Janeiro e mestre em Relações Étnico-raciais pelo Cefet-RJ.

ii Doutorado em andamento no ProPed, UERJ. Mestre em Educação pelo PPGEduc da UFRRJ. Especialista em Arte-terapia Educação e saúde pela UCAM. Graduado em Educação Artística pela Escola de Belas Artes da UFRJ e professor de Artes Visuais do INES. Desenvolve pesquisas no campo das Artes Visuais, em especial a produção afro-brasileira imbricadas na Educação e no Ensino da Arte.

Enviado em: 29 de maio de 2017.

Aprovado em: 16 de junho de 2017. 